\title{
A Qualitative Study of Thermochemical Degradation Related with Concrete and Mortar Strength
}

\author{
José Mora-Ruacho' ${ }^{1}$ and Humberto A. Monreal-Romero ${ }^{2}$ \\ ${ }^{1}$ School of Engineering, Research and Post-Graduate Studies, Autonomous University of Chihuahua, New Campus, \\ 31125 Chihuahua, Mexico \\ ${ }^{2}$ Biomaterials Department, School of Dentistry, Autonomous University of Chihuahua, Campus I, 31125 Chihuahua, Mexico
}

Correspondence should be addressed to José Mora-Ruacho; jmora@uach.mx

Received 30 November 2014; Accepted 10 March 2015

Academic Editor: Alfonso Castiñeiras

Copyright (C) 2015 J. Mora-Ruacho and H. A. Monreal-Romero. This is an open access article distributed under the Creative Commons Attribution License, which permits unrestricted use, distribution, and reproduction in any medium, provided the original work is properly cited.

\begin{abstract}
The nondestructive methods applied to the evaluation of concrete use different parameters to be related in the estimated resistance of concrete or other properties. The conducted study has evaluated a qualitative method of thermochemical degradation in concrete and mortar using a solvent acid whose chemical energy is capable of degrading the material. The reported study consisted in performing laboratory tests on mechanical compressive strength of concrete and mortar and thermochemical tests performed on little cores of concrete or mortar immersed in hydrochloric acid contained in a calorimeter system, obtaining several parameters as the time of thermal equilibrium, increase of temperature, degradation energy, and mass loss due to the thermochemical reaction. From the obtained results, these variables were analyzed and served as a parameter to be related with the concrete or mortar strength. The best parameter proved to be a good estimator was the increase of temperature and its degradation energy, whose value was inversely proportional to the strength of the material. Also, it is found that the most significant mechanisms that influenced the thermochemical reaction are the calcium content and the water chemically bound in the cement paste to perform the thermochemical test.
\end{abstract}

\section{Introduction}

The activities of repair and rehabilitation of concrete structures are a more viable option for many countries. This is because a good deal of its gross domestic product, GDP, had used this provision in the investment of construction of infrastructure, regarding the use of concrete in its different modalities and uses. What goes before to any repair and rehabilitation is the inspection activity and evaluation, where the in situ or nondestructive tests to the concrete have had a considerable attention in use and development. As a result of the above, a considerable number of techniques, gadgets, and in-place evaluation methods performed in existing concrete structures or in construction have been increased.

In the inspection and evaluation activity in concrete structures, although some characteristics of the material such as its density or permeability can be relevant, one of the most important characteristics has been its resistance. In the characterization of the material, there is a wide availability of methods [1-4]. The nondestructive methods are those that do not affect the performance of the structural element and those called partially destructive, causing a focused damage, as the methods of rebound, penetration, pull-out, break-off, internal fracture, and so forth [5-8]. On the other hand, there are methods considered destructive where a sample is extracted, taken directly from the structure as the extraction of large core samples [9].

Most of the methods employ a mechanical energy being dynamic or static to obtain a parameter related to the resistance or other. The nature of the testing equipment reported can vary from simple devices, to the ones that are complex and expensive and that probably may require a special or complicated preparation.

At the present, the reported literature about chemical testing of hardened concrete is limited to the identification of causes of deterioration, such as sulphates, chlorides or alkali 
determination, cement content, and aggregate/cement ratio. Water/cement ratio and hence strength have been difficult to assess to any worthwhile degree of accuracy, and direct chemical methods are of limited value in this respect [1014]. Further, its use has been extended to the quantitative determination, by which it has not been possible to reach an adequate range of accuracy, considering that the quantitative procedures and techniques are complex in general.

Considering the above mentioned, this study pretends to make a qualitative analysis to associate the values in $w / c$ ratios and hence strength of the material and a parameter resulting from the tests of the thermochemical reaction by the application of a strong acid capable of partially dissolving concrete or mortar. This proposed method can be considered as a partially destructive technique and according to its performance, it can be considered a technique in potential use to the estimation of the in-place concrete strength.

\section{Theoretical and Methodological Basis}

2.1. Theoretical Basis of the Thermochemical Degradation. The thermochemical degradation mechanism explained here is about the chemical processes that the material follows when it is in contact with hydrochloric acid, $\mathrm{HCl}$, and which of the components have the strongest influence in this process.

The setting and hardening of a cement paste are the result of some physical and chemical processes in cement and water. From the main hydration products in cement paste it is important to identify the next components [15] expressed in the accustomed terms used in cement:

\section{Calcium Silicates}

(i) $2 \mathrm{C}_{3} \mathrm{~S}$ (tricalcium silicate) $+11 \mathrm{H}$ (water) $\rightarrow \mathrm{C}_{3} \mathrm{~S}_{2} \mathrm{H}_{8}$ $(\mathrm{C}-\mathrm{S}-\mathrm{H})+3 \mathrm{CH}$ (calcium hydroxide)

(ii) $2 \mathrm{C}_{2} \mathrm{~S}$ (dicalcium silicate) $+9 \mathrm{H}$ (water) $\rightarrow \mathrm{C}_{3} \mathrm{~S}_{2} \mathrm{H}_{8}$ (C$\mathrm{S}-\mathrm{H})+3 \mathrm{CH}$ (calcium hydroxide)

\section{Tricalcium Aluminate}

(i) $\mathrm{C}_{3} \mathrm{~A}$ (tricalcium aluminate) $+3 \mathrm{CS}^{-} \mathrm{H}_{2}+26 \mathrm{H}$ (water) $\rightarrow \mathrm{C}_{6} \mathrm{AS}_{3}{ }^{-} \mathrm{H}_{32}$ (ettringite)

\section{The Ferrite Phase}

(i) $\mathrm{C}_{4} \mathrm{AF}+3 \mathrm{CS}^{-} \mathrm{H}_{2}+21 \mathrm{H} \rightarrow \mathrm{C}_{6}(\mathrm{~A}, \mathrm{~F}) \mathrm{S}_{3}{ }^{-} \mathrm{H}_{32}+(\mathrm{F}, \mathrm{A}) \mathrm{H}_{3}$ of the most important and special aluminate compounds.

On the other hand, if aggregates are limestone based, their main components are the calcium carbonate, $\mathrm{CaCO}_{3}$, and calcium carbonate of magnesium, $\mathrm{CaMg}\left(\mathrm{CO}_{3}\right)_{2}$.

Under the principle of solubility, which is the capacity of a substance to be dissolved notoriously with another, an acid can be used to dissolve inorganic solid substances. The hydrochloric acid, $\mathrm{HCl}$, appears to be suitable for performing chemical tests [1]. To perform a chemical reaction, the $\mathrm{HCl}$ requires a watery surrounding which must be present in the paste-aggregate material and the acid itself.

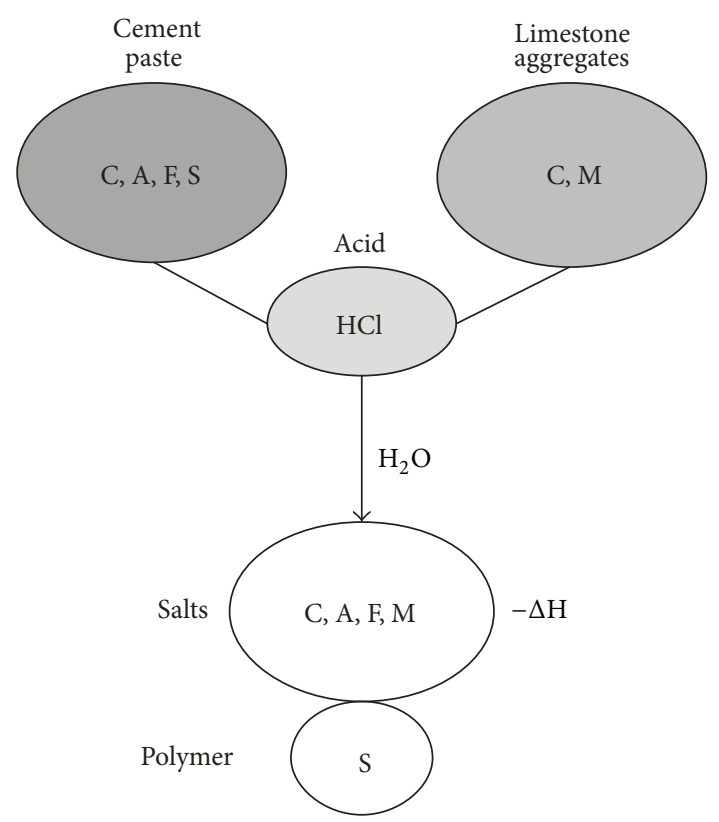

FIGURE 1: Resumed scheme of the influence of the chemical components of cement and aggregates involved in the thermochemistry.

Figure 1 shows a scheme in which the chemical components are resumed that can influence the thermochemistry of this system in contact with $\mathrm{HCl}$ not discarding the water and other minerals. The cement paste components (whose approximate percentages in mass are [15]: $\mathrm{C}=64 \%, \mathrm{~A}=4.5 \%$, $\mathrm{F}=2.4 \%$ and $\mathrm{S}=22 \%$ ) and aggregate (whose approximate percentages in mass are: $\mathrm{CaO}=30.4-56 \%, \mathrm{Mg}=0-21.9 \%$ and $\mathrm{CO}_{2}=42.5 \%$ ) in contact with $\mathrm{HCl}$ will form salts based on $\mathrm{C}$, $\mathrm{A}, \mathrm{F}, \mathrm{M}$ with exothermic heat release and $\mathrm{S}$ polymer acids, with this being endothermic. $\mathrm{S}$ forms in $\mathrm{HCl}$ an unstable siliceous acid which is polymerized with reversibility [16]. With the heat release of exothermic origin being the base of this study, the influence of the S product is discarded. It is observed then that calcium has the major percentage in the composition of cement and aggregate, and S, although having a considerable percentage, is negligible in its influence of the heat release. On the other hand, $\mathrm{A}$ and $\mathrm{F}$ will have a reduced influence in the heat release due to low percentage contents. The main influence will be given by the calcium in the cement paste. Now the strong influence of calcium in the process is described.

Every chemical reaction is characterized by a change on temperature, $\Delta T$, which depends on molar concentration of reagents and on a change in molar enthalpy, $\Delta H$. Enthalpy is the amount of caloric energy of a substance that can be interchangeable with its environment. A positive $\Delta H$ shows endothermic reactions and a negative $\Delta H$ presents exothermic reactions [17].

To evaluate the thermodynamics of reactions calculating its enthalpy, the Hess law [17] can be applied according to the scheme of a general isobaric reaction as shown in

$$
a \mathrm{~A}+b \mathrm{~B} \longrightarrow c \mathrm{C}+d \mathrm{D}
$$


where $a$ and $b$ are the number of moles on the reagents $\mathrm{A}$ and $\mathrm{B}$, respectively, $c$ and $d$ are the number of moles of the products on the reactions $\mathrm{C}$ and $\mathrm{D}$, respectively, as shown in

$$
\Delta H=\left(c \Delta H_{\mathrm{C}}+d \Delta H_{\mathrm{D}}\right)-\left(a \Delta H_{\mathrm{A}}+b \Delta H_{\mathrm{B}}\right) .
$$

The enthalpy of the reaction, $\Delta H$, is equal to the difference between the sum of formation enthalpies of the products $\Delta H_{\mathrm{C}}$ and $\Delta H_{\mathrm{D}}$ of the reaction and the reagents $\Delta H_{\mathrm{A}}$ and $\Delta H_{\mathrm{B}}$, taking into account the molar reaction between them.

By making a stoichiometric analysis of the calcium as the main component in the material, the ionic equation shown in (3) describes the process. The calcium cations react with the chloride anion coming from the $\mathrm{HCl}$, giving as a result calcium chloride, $\mathrm{CaCl}_{2}$ [17]:

$$
\mathrm{Ca}^{2+}+2 \mathrm{Cl}^{-} \longrightarrow \mathrm{CaCl}_{2} \text {. }
$$

During the reaction, the calcium of cement paste will react better than aggregate calcium due to the limited dissolution in the carbonates contained, its particle size, and its low water contents. The material-acid reactions in calcium that might describe best the material degradation based on enthalpy are the following:

$$
\begin{array}{r}
\mathrm{CaCO}_{3}+2 \mathrm{HCl} \longrightarrow \mathrm{CaCl}_{2}+\mathrm{H}_{2} \mathrm{O}+\mathrm{CO}_{2} \\
\Delta H=-81.1 \mathrm{~kJ} / \mathrm{mol} \\
\mathrm{CaO}+2 \mathrm{HCl} \longrightarrow \mathrm{CaCl}_{2}+\mathrm{H}_{2} \mathrm{O} \\
\Delta H=-546.4 \mathrm{~kJ} / \mathrm{mol} \\
\mathrm{Ca}(\mathrm{OH})_{2}+2 \mathrm{HCl} \longrightarrow \mathrm{CaCl}_{2}+2 \mathrm{H}_{2} \mathrm{O} \\
\Delta H=-829.2 \mathrm{~kJ} / \mathrm{mol}
\end{array}
$$

The resulting approximated enthalpy in (4) of $-81.1 \mathrm{~kJ} / \mathrm{mol}$ is coming from the limestone aggregates (if this material is used in place of siliceous aggregate) and in (5) and (6) the enthalpy of -546.4 and $-829.2 \mathrm{~kJ} / \mathrm{mol}$ for an ordinary cement paste is shown. The latter, having more enthalpy, confirms that the calcium of paste cement is the one that reacts easier [18]. It should be mentioned that a complete thermochemical evaluation of the system is more complex than the one presented in (4) to (6). In its energetic balance, other reactions contribute such as reversible dissociations. Nevertheless the previous analysis mentioned above is satisfactory as a solid foundation to the experiments.

At one point, when the material-HCI system achieves its thermal balance, the chemical reaction will stop by the waste of one of the reactors or by establishing the balance between all the components. In practical terms, the Zero Thermodynamic Law establishes that two or more bodies will be in thermal balance if and only if their temperature is the same [19]. This is a simple reason to establish that when there is no more temperature rising, it can be settled that the reaction is finished.

The principle of this study is to determine a relationship between the needed chemical energies to degrade concrete or mortar of a given compressive strength qualitatively. Such

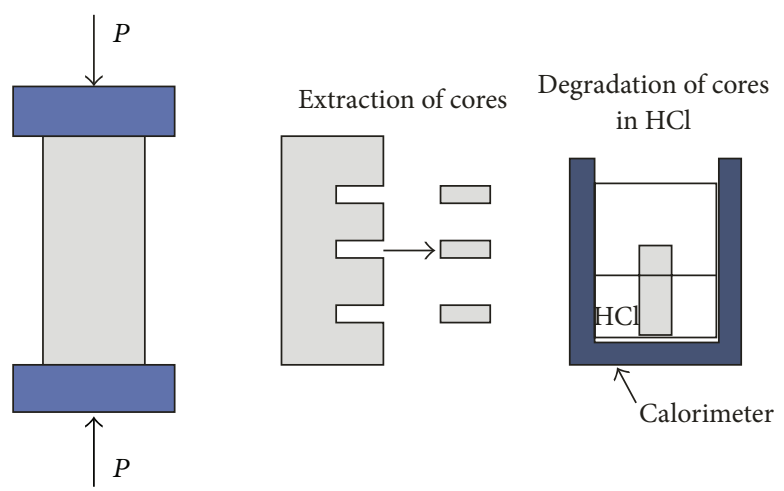

(a) Compressive strength test

(b) Chemical degradation test

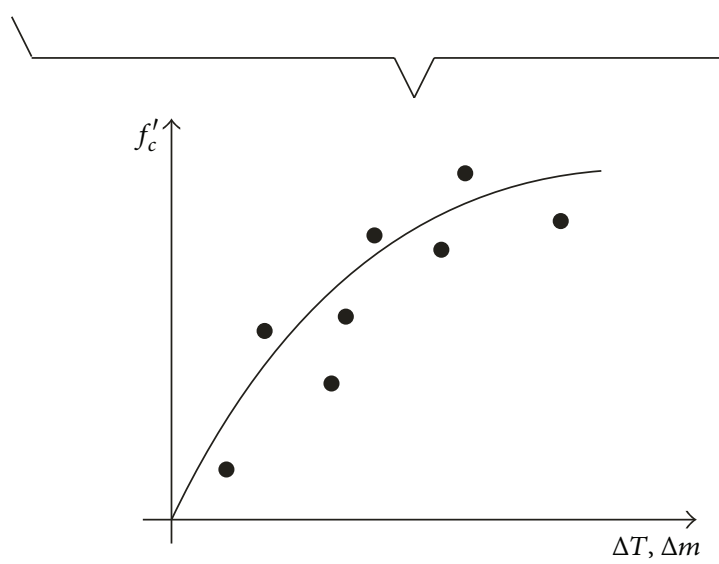

(c) Obtaining of curves

FIGURE 2: Scheme of the experimental program.

energy is based upon the chemical reaction the $\mathrm{HCl}$ acid will produce. In this case the HCI in contact with samples of concrete and mortar of different compressive strength values was made.

\subsection{Experimental Procedure}

2.2.1. Experimental Program. Figure 2 shows the configuration of the experimental procedure schematically. Four standard cylinders to fabricate concrete and mortar of $150 \mathrm{~mm}$ diameter and $300 \mathrm{~mm}$ height were made. Three of them were used for the compressive strength test and from the fourth cylinder three little cores were extracted. Each core was tested in the calorimeter with $\mathrm{HCl}$ and temperature increase, mass loss, and time of thermal equilibrium were obtained. The experimental program was done to determine curves in temperature increase-compressive strength and mass losscompressive strength in concretes and mortar.

2.2.2. Materials Used. For this study, concrete and mortar were produced with Portland cement of 10 water-cement ratios, $w / c$ of $0.40,0.45,0.50,0.55,0.60,0.65,0.70,0.75$, 0.80 , and 0.85 , whose dosages for concrete and mortar are shown in Tables 1 and 2, respectively. For mortars, the relationship cement-sand was of 0.5 . Water used for the 
TABLE 1: Dosages of concrete.

\begin{tabular}{|c|c|c|c|c|}
\hline$w / c$ & Water, $\mathrm{kg} / \mathrm{m}^{3}$ & $\begin{array}{c}\text { Cement, } \\
\mathrm{kg} / \mathrm{m}^{3}\end{array}$ & $\begin{array}{c}\text { Fine } \\
\text { aggregate, } \\
\mathrm{kg} / \mathrm{m}^{3}\end{array}$ & $\begin{array}{l}\text { Coarse } \\
\text { aggregate, } \\
\mathrm{kg} / \mathrm{m}^{3}\end{array}$ \\
\hline 0.40 & \multirow{10}{*}{216.0} & 539.1 & 625.5 & \multirow{10}{*}{942.0} \\
\hline 0.45 & & 478.8 & 675.6 & \\
\hline 0.50 & & 431.6 & 714.9 & \\
\hline 0.55 & & 389.4 & 750.0 & \\
\hline 0.60 & & 362.1 & 772.6 & \\
\hline 0.65 & & 332.4 & 797.4 & \\
\hline 0.70 & & 309.9 & 816.1 & \\
\hline 0.75 & & 289.2 & 833.3 & \\
\hline 0.80 & & 270.3 & 849.0 & \\
\hline 0.85 & & 253.0 & 863.4 & \\
\hline
\end{tabular}

TABle 2: Dosage of mortars.

\begin{tabular}{lccc}
\hline$w / c$ & Water, $\mathrm{kg} / \mathrm{m}^{3}$ & Cement, $\mathrm{kg} / \mathrm{m}^{3}$ & Coarse aggregate, $\mathrm{kg} / \mathrm{m}^{3}$ \\
\hline 0.40 & 269.2 & 626.7 & 1271.7 \\
0.45 & 289.2 & 602.5 & 1223.3 \\
0.50 & 308.3 & 580.8 & 1179.2 \\
0.55 & 325.0 & 560.8 & 1138.3 \\
0.60 & 341.7 & 541.7 & 1100.0 \\
0.65 & 356.7 & 524.2 & 1064.2 \\
0.70 & 370.8 & 507.5 & 1030.0 \\
0.75 & 384.2 & 491.7 & 999.2 \\
0.80 & 396.7 & 477.5 & 969.2 \\
0.85 & 408.3 & 463.3 & 940.8 \\
\hline
\end{tabular}

mixtures was taken from the general drinking water net of the city, the Portland cement used was of type CPC 30R, and sand and coarse aggregate were crushed limestone with a maximum aggregate size of $19 \mathrm{~mm}$. The graduation of the fine and coarse aggregates complied with the ASTM C33/C33-13 Standard [20]. As a workability admixture, a nonionic kind superplasticizer was used.

On the other hand, the hydrochloric acid characteristics (HCI) were the following: commercial concentration, 36\%; concentration used in the test, $1: 1$; acid-water (19.5\%); specific gravity, $1.098 \mathrm{~kg} / \mathrm{lt}$; approximated specific heat, $2990 \mathrm{~J} / \mathrm{kgK}$; boiling point, $108^{\circ} \mathrm{C}$; and molar mass, $36.4 \mathrm{gr} / \mathrm{mol}$.

2.2.3. Preparation and Test. The fabrication of concrete and mortar was done by a commonly used construction conventional mixer. The compacting and curing followed the recommendations of ASTM C192-12 Standard [21]. For the compressive strength to 28 days of age, four cylinders of 150 diameter $\times 300 \mathrm{~mm}$ height by each series of produced concrete and mortar were used, following the recommendations of the ASTM C39M-12 Standard [22].

For the chemical degradation test, three little cores of $35 \mathrm{~mm}$ diameter and at least $100 \mathrm{~mm}$ height were extracted from one standard $150 \times 300 \mathrm{~mm}$ cylinder with a diamond

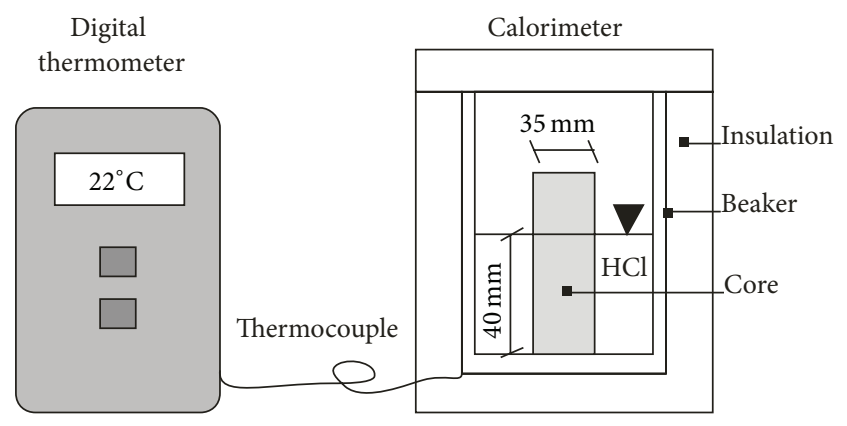

FIGURE 3: Calorimeter and digital thermometer.

core bit. This standard cylinder was fabricated as the abovementioned but designed for not being tested in compression as the others. Thus, the little core was subjected to be degraded in hydrochloric acid. For this test a little calorimeter was built (Figure 3) capable of containing the hydrochloric acid in contact with the little core. The calorimeter consisted in a glass beaker with a $250 \mathrm{~mL}$ capacity, covered on its external wall with a thermal insulation. In each test, $100 \mathrm{~mL}$ of acid was added to the calorimeter. With this volume, the core was kept immersed to $40 \mathrm{~mm}$ depth. The contact surface of each core was then $4400 \mathrm{~mm}^{2}$. The calorimeter function was to prevent heating transference to nondesirable environments. Thus this test was repeated three times for each series of concrete and mortar. To measure the temperature, a digital thermometer series $6802 \mathrm{II}$ with $0.1^{\circ} \mathrm{C}$ accuracy was used and it was provided by a thermocouple type $\mathrm{K}$ which was placed in the bottom between the interface of the insulation and the glass external wall. The measuring of temperature was at 30-second intervals. For measuring the loss of mass a scale Ohaus Scout-Pro with an accuracy of $0.1 \mathrm{gr}$ was used. Thus, the test ended when the temperature was kept constant (i.e., the increase of temperature was zero).

\section{Results and Discussion}

3.1. Observations on the Thermochemical Degradation. The thermochemical degradation of concrete and mortar cores with the hydrochloric acid generated a temperature increase in the system as it was theoretically described. During the evolution of the test, it was also observed that foam was released as a product of the $\mathrm{CO}_{2}$ present mainly in the concrete or mortars with high water-cement ratios. The reason for releasing of $\mathrm{CO}_{2}$ can be the stronger reaction with the carbonates present in limestone of aggregates being easier to be attacked in high water-cement ratios.

The core samples were not totally dissolved, but the test was sufficiently effective to dissolve the superficial layer and part of the aggregates as in the concrete case as shown in Figure 4.

The time when the thermal equilibrium was reached, that is, no change in temperature interval or temperature increase was zero for both concrete and mortar, was in a range of 8.5 to 11.5 minutes. In this value range, curves $\Delta T$-compressive 


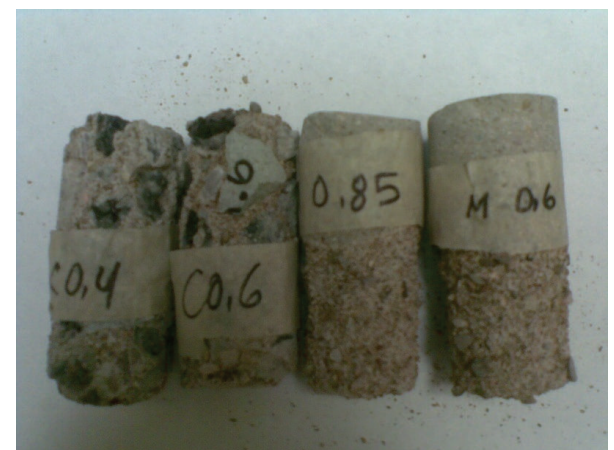

FIgURE 4: Typical degradation observed in concrete and mortar cores.

strength and $\Delta T$-mass loss can be observed and discussed, and they are mentioned ahead.

In general terms, it should be observed that as consequence of the acid being in contact with all the components of the concrete or mortar samples, different reactions for the paste and for the fine and coarse aggregates can be expected, as they are of different composition and content percentage. Thus, it is complex to establish relationships of the contribution of each one of the elements in the strength of the material.

3.2. Curves $\Delta T$-Compressive Strength. The obtained results in the temperature increase, $\Delta T$-compressive strength, $f_{c}^{\prime}$, for the concrete and mortar are shown in Figure 5 with their respective tendency curves. Every value in water-cement, $w / c$, ratio in concrete and mortar is consistent with the expected compressive strength, whose average values ranged from 12.4 to $45.1 \mathrm{MPa}$. Equations (7) show the resultant values of the tendency curves of Figure 5 in the strength prediction, $f_{c}^{\prime}$, in function of temperature increase, $\Delta T$ :

$$
\begin{gathered}
\text { Concretes: } f_{c}^{\prime}=178-16 \Delta T, \quad R^{2}=0.98[\mathrm{MPa}] \\
\text { Mortars: } f_{c}^{\prime}=90-6.4 \Delta T, \quad R^{2}=0.96[\mathrm{MPa}] .
\end{gathered}
$$

As it was mentioned above, the temperature reached the thermal equilibrium between 8.5 and 11.5 minutes. The time does not appear to be a reliable parameter in the resistance estimation because it is not proportional to it. It is only a parameter in these tests that helped to determine the time of duration in which thermal equilibrium was reached.

On the other hand, the temperature increase, $\Delta T$, and correspondent compressive strength, $f_{c}^{\prime}$, for each one of these concretes and mortars resulted inversely proportional. In this case, the concrete and mortar used approximate ranges of 8.5 to $10.5^{\circ} \mathrm{C}$ and 7.5 to $11.0^{\circ} \mathrm{C}$, respectively.

A relationship between compressive strength, $f_{c}^{\prime}$, and energy, $Q$ (which depends directly on $\Delta T$ ), can be compared theoretically with the results shown in Figure 5. When the work, $W$, employed to degrade the material is equal or equivalent to the degradation energy given by the acid, this energy can be expressed by the following equation [23]

$$
Q=m c \Delta T,
$$

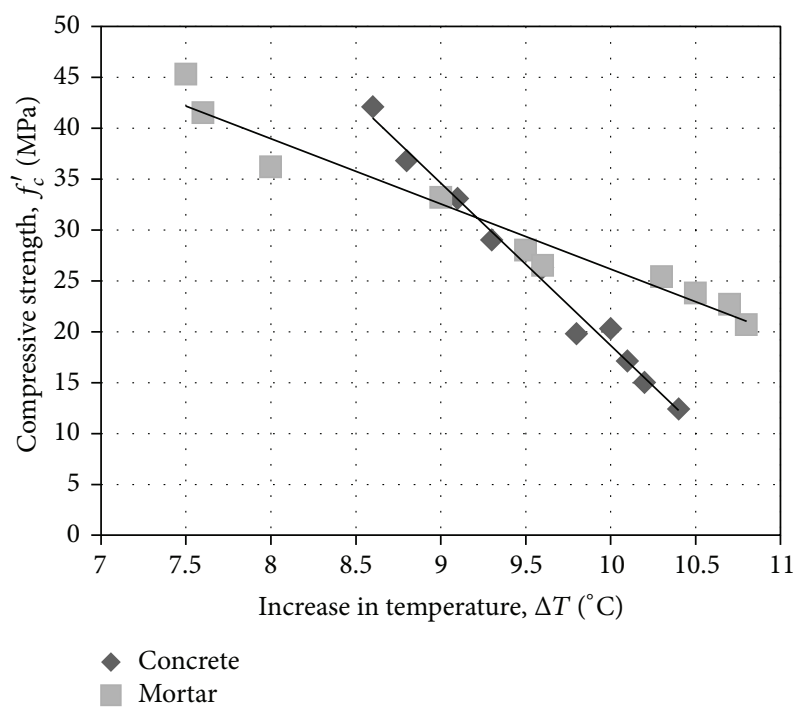

FIGURE 5: Relationship of temperature increase and compressive strength in concrete and mortar.

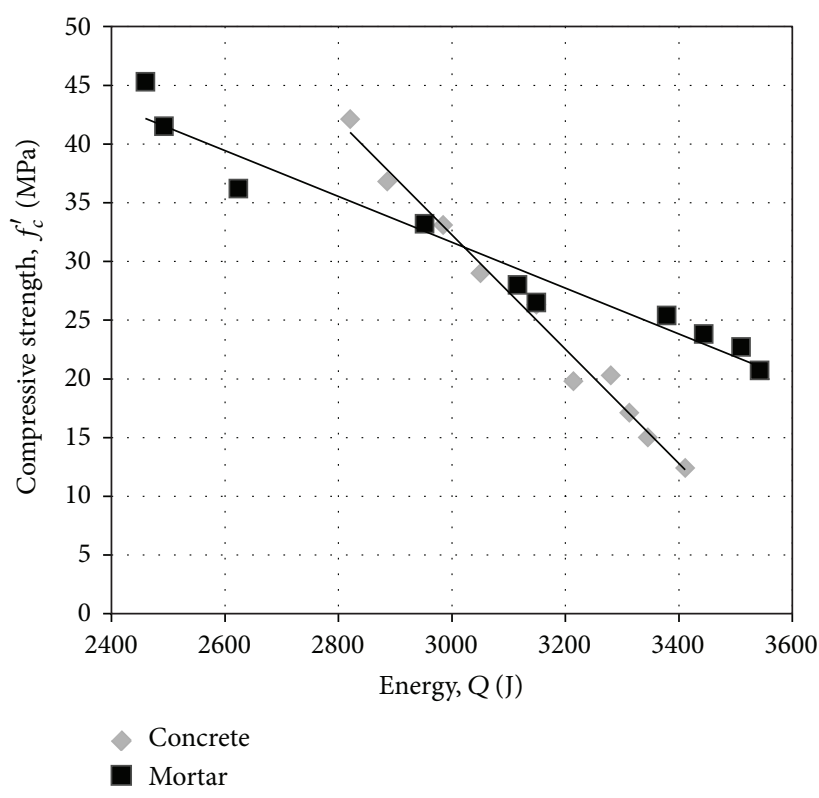

FIGURE 6: Relationship of compressive strength and released energy.

where $Q$ is the heat released from the reaction, the one that has been used in degrading the material. $m$ is the mass of the hydrochloric acid used, in this case $0.1098 \mathrm{~kg}$ (considering that its evaporation is minimal), $c$ is the specific heat of the acid, being $2990 \mathrm{~J} / \mathrm{kgK}$ (considering that it prevails constant with the change on temperature), $\Delta T$ is the increase of temperature that the acid experimented for each test. If $Q$ is expressed in function of $\Delta T$ on (8), then $Q=0.1098 \times$ $2990(\Delta T)$, where $Q \approx 328(\Delta T)$. In general, if the values of $\Delta T$ go from 7.5 to $11^{\circ} \mathrm{C}$, the resultant value of $Q$ can be determined and be plotted versus $f_{c}^{\prime}$ whose values are presented in Figure 6. 


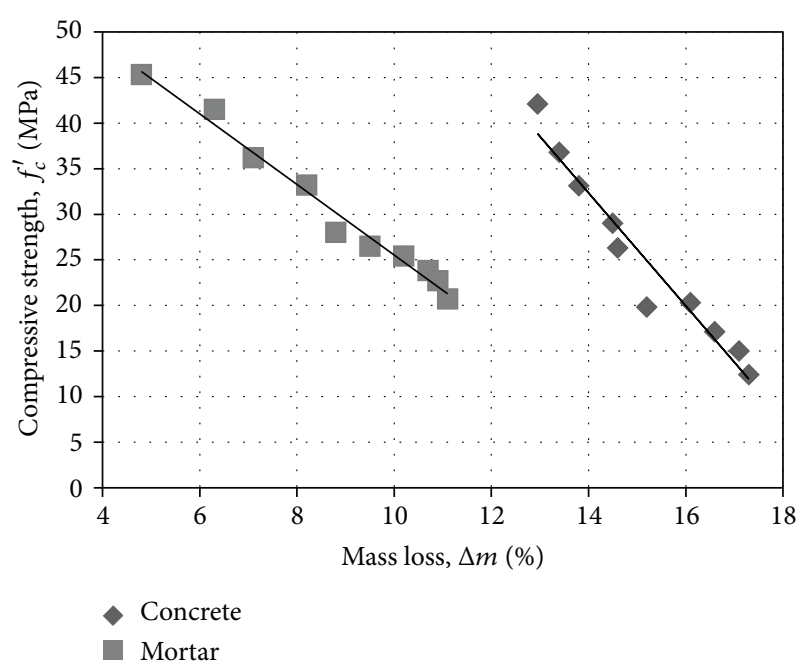

Figure 7: Relationship of mass loss and compressive strength.

Figure 6 confirms that the energy, $Q$, used by the acid is inversely proportional to compressive strength for both materials. This fact appears to be apparently paradoxical because in this mechanism, more energy would be used to perform a task to disintegrate the material. Nevertheless, it can be seen that an acid has potential energy to degrade a material and depends directly on the water content chemically and physically bonded in the material. Thus, it is important to mention that the amount of water and the amount of reagents that form salts with $\mathrm{HCl}$ are the conditions to carry out the releasing of energy. The hydrated paste of cement, aggregates based on limestone, and the water contained in the used acid are elements that encourage the reaction. On the other hand, the material strength depends basically on its $w / c$ ratio and this is inversely proportional to strength [15]. If the amount of water is variable in the $w / c$ relationship and if the other elements that cause the reaction are maintained more or less constant, then minor reaction energy in low $w / c$ relationships is available because there is a less amount of water. This is the reason why a minor availability of energy was shown in the concretes or mortars with low $w / c$ ratios.

3.3. Curves Mass Loss-Compressive Strength. The curves mass loss-compressive strength is shown in Figure 7. As a result of the chemical reaction where part of the material was dissolved, the mass loss appeared to be a direct function of the behaviors shown in Figures 5 and 6 . The mass loss can be a redundant parameter but useful in helping as a comparative or confirmatory in the behavior. It is observed that the concretes showed a major mass loss $(\approx 13$ to $17 \%)$ compared to the mortars ( $\approx 5$ to $11 \%$ ). The possible reason for a major mass loss is that the specific surface of grains and cement content of concrete and mortar were exposed to the acid.

\section{Conclusions}

The preliminary study of this methodology in the estimation of concrete strength has led to the following conclusions.
The method that uses chemical energy as a means for transforming the material properties in this case by dilution acquires an advantage facing other existent methods. Thus, relatively complex mechanisms and equipment using other types of energy can be avoided, the method is simple as it uses elements easy to find in field or laboratory.

As theoretically explained above, an important part of the chemical reaction with $\mathrm{HCl}$ is performed in the calcium being of major percentage in cement paste and aggregates. Of these two, the reaction is more noticeable in the paste for having more enthalpy than aggregates, which proves that it will be easier to react than aggregate. Thus, the released exothermic heat assumed comes in a large majority from the reaction of calcium and a slow percentage of aluminium, magnesium, and iron. However, although silica is an important content in the paste, the reaction is endothermic and it will not generate heat and its effect can be negligible in the measurements of increase of temperature.

In the analysis of the variables used as parameters in this study, the variable of time does not appear to be a suitable indicator to be used as a parameter in the strength estimation, but rather it has helped as an estimator in the duration of the tests. It can be considered that a test of this type can reach its thermal equilibrium from 8.5 to 11.5 minutes for both materials. Thus, the execution time of this test is fast in obtaining results.

There is a clear relationship between the temperature increase parameter and the material strength, which is that the temperature increase is inversely proportional to the material strength. The heat, $Q$, is a relationship dependent on $\Delta T$ and is inversely proportional to the material strength and it is apparently paradoxical. However, the heat availability to degrade the material depends directly between other factors on the amount of water in the $w / c$ relationship, finding that having a less quantity of water in a low $w / c$ relationship has a major resistance and as a consequence there will be less energy to be used in degrading the material. The loss of mass appeared to be a redundant variable but useful just as comparative or complement of a test.

Finally, trying to explain some differences in behaviors shown in concrete and mortar, they do not deserve more relevance than the one that could be made from an analysis in a separate study and that accounts for the influence of the size and aggregate and cement content and other variables involved in the behavior to be analyzed. The matters that have to be taken into account are security and provisions that cover the inherent risks as every chemical test that uses strong solvents as the acid used in this test.

This method could enable more than estimating the resistance of material, based on Portland cement, to be useful in estimating the cement and aggregate content in a fast way, being a more complete test in the characterizing of the material.

\section{Conflict of Interests}

The authors declare that there is no conflict of interests regarding the publication of this paper. 


\section{Acknowledgments}

The authors want to show their acknowledgments to Miloslava Axmannová, Jacobo Chávez, and Irma Peralta from the Laboratory of Chemistry of the School of Engineering UACH for their kindness, availability, and help in providing the materials and the chemical tests made. They also want to thank the staff of the Laboratory of Materials of the School of Engineering UACH for their professional help in characterizing the materials. In the same way, they plenty thank Grupo Cementos de Chihuahua for the donation of the materials used in this study.

\section{References}

[1] J. H. Bungey and S. G. Millard, Testing of Concrete in Structures, Chapman \& Hall, Blackie Academic \& Professional, Glasgow, UK, 1996.

[2] V. M. Malhotra and N. Carino, Handbook on Nondestructive Testing of Concrete, edited by: V. M. Malhotray, N. J. Carino, CRC Press, West Conshohocken, Pa, USA, 2004.

[3] American Concrete Institute (ACI), In-Place Methods to Estimate Concrete Strength, vol. 228, American Concrete Institute, Detroit, Mich, USA, 2011.

[4] A. E. Long, G. D. Henderson, and F. R. Montgomery, "Why assess the properties of near surface concrete? Near-surface testing for strength and durability of concrete," in Proceedings of the 5th CANMET/ACI International Conference on Durability of Concrete, P. A. M. Basheer, Ed., Barcelona, Spain, 2000.

[5] ASTM (American Society for Testing and Materials), "Standard test method for rebound number of hardened concrete," in Annual Book of ASTM Standards, ASTM C805-13, ASTM, West Conshohocken, Pa, USA, 2013.

[6] ASTM (American Society for Testing and Materials), "Standard test method for penetration resistance of hardened concrete," Tech. Rep. ASTMC803/C803M-03-10, Annual Book of ASTM Standards, West Conshohocken, Pa, USA, 2010.

[7] American Society for Testing and Materials (ASTM), Standard Test Method for Pullout Strength of Hardened Concrete. ASTM C900-13, Annual Book of ASTM Standards, American Society for Testing and Materials, West Conshohocken, Pa, USA, 2013.

[8] ASTM (American Society for Testing and Materials), "Standard test method for the break-off number of concrete," Tech. Rep. ASTM C1150-96, Annual Book of ASTM Standards, West Conshohocken, Pa, USA, 1996.

[9] ASTM (American Society for Testing and Materials), "Standard test method for obtaining and testing drilled cores and sawed beams of concrete," in Annual Book of ASTM Standards, ASTM C42/C42M-13, ASTM, West Conshohocken, Pa, USA, 2013.

[10] American Society for Testing and Materials (ASTM), Standard Test Method for Potential Alkali-Silica Reactivity of Aggregates (Chemical Method). ASTM C289-07, Annual Book of ASTM Standards, American Society for Testing and Materials, West Conshohocken, Pa, USA, 2007.

[11] ASTM, "Standard test method for acid soluble chloride in mortar and concrete," in Annual Book of ASTM Standards, ASTM C1152-04, American Society for Testing and Materials, West Conshohocken, Pa, USA, 2004.

[12] ASTM (American Society for Testing and Materials), "Standard test method for expansion and hydraulic cement mortar bars stored in water," in Annual Book of ASTM Standards, ASTM C1038-10, ASTM, West Conshohocken, Pa, USA, 2010.

[13] British Standards Institution, "Part 124, methods of testing concrete: analysis of hardened concrete," BS 1881, British Standards Institution, Londres, UK, 1988.

[14] ASTM (American Society for Testing and Materials), "Standard test method for cement content of hardened portland cement concrete," Tech. Rep. ASTM C85-88, Annual Book of ASTM Standards, West Conshohocken, Pa, USA, 1988.

[15] S. Mindess, J. F. Young, and D. Darwin, Concrete, Prentice-Hall, Pearson Education, Upper Saddle River, NJ, USA, 2nd edition, 2002.

[16] C. Chambers and A. K. Hollyday, Modern Inorganic Chemistry: An Intermediate Text, Butterworths, London, UK, 1975.

[17] A. G. Whittaker, A. R. Mount, and M. R. Heal, Physical Chemistry, Instant Notes Series, BIOS Scientific Publishers, Oxford, UK, 2000.

[18] P. C. Hewlett, Ed., LEA's Chemistry of Cement and Concrete, Elsevier, New York, NY, USA, 4th edition, 2005.

[19] R. D. Levine, "Book review: encyclopedia of chemical physics and physical chemistry. Edited by John H. Moore and Nicholas D. Spencer," ChemPhysChem, vol. 3, no. 9, pp. 821-822, 2002.

[20] ASTM (American Society for Testing and Materials), "Standard specification for concrete aggregates," in Annual Book of ASTM Standards, ASTM C33/C33M-13, ASTM, West Conshohocken, $\mathrm{Pa}$, USA, 2013.

[21] ASTM (American Society for Testing and Materials), "Standard practice for making and curing concrete test specimens in the laboratory," in Annual Book of ASTM Standards, vol. 04.02, ASTM C192/C192M-12, ASTM, West Conshohocken, Pa, USA, 2012.

[22] ASTM, "Standard test Method for compressive strength of cylindrical concrete specimens," in Annual Book of ASTM Standards, ASTM C39/C39M-12, American Society for Testing and Materials, West Conshohocken, Pa, USA, 2012.

[23] Y. A. Cengel and M. A. y Boles, Termodinámica, McGraw-Hill, Santa Fé, México, 6th edition, 2008. 

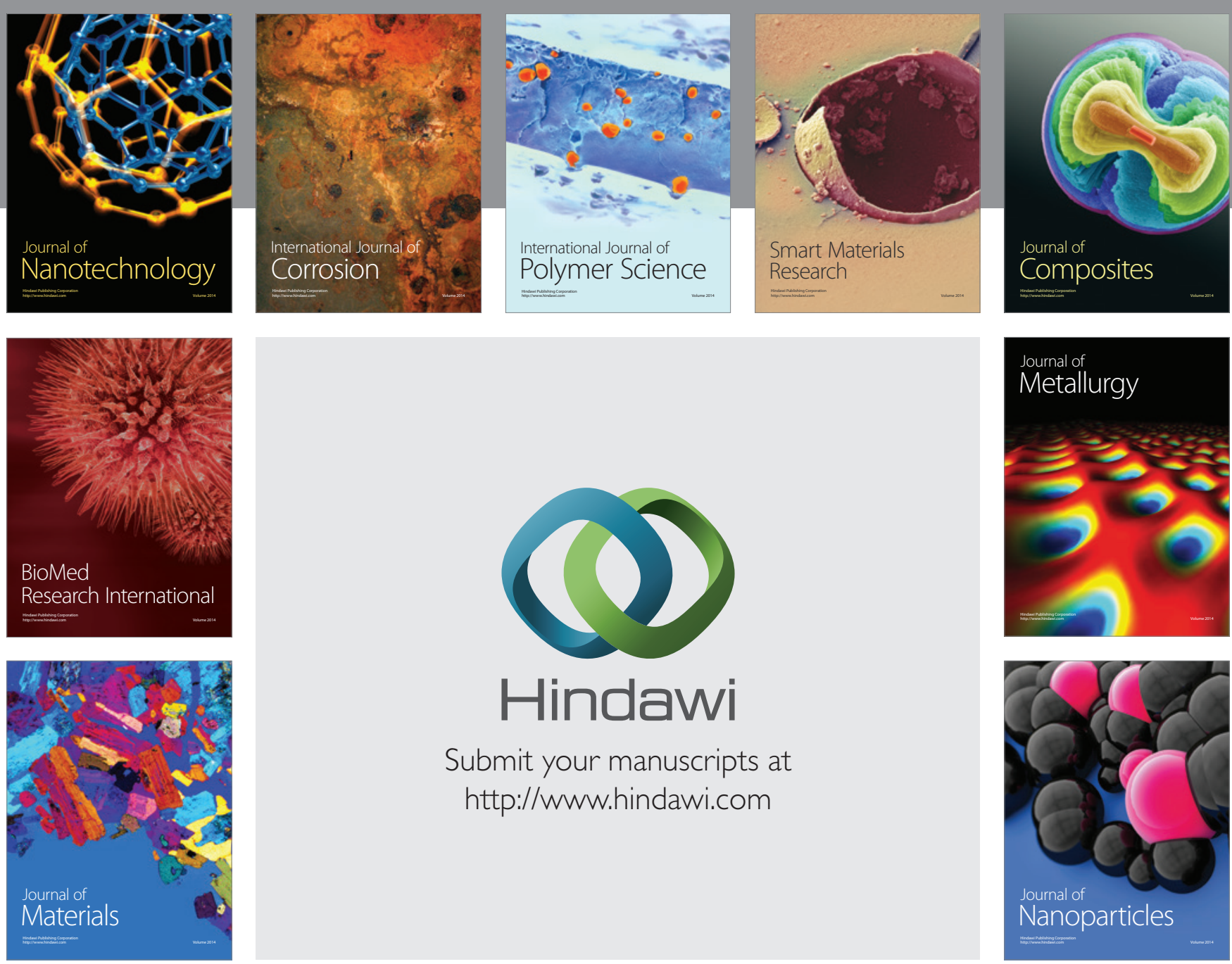

Submit your manuscripts at http://www.hindawi.com
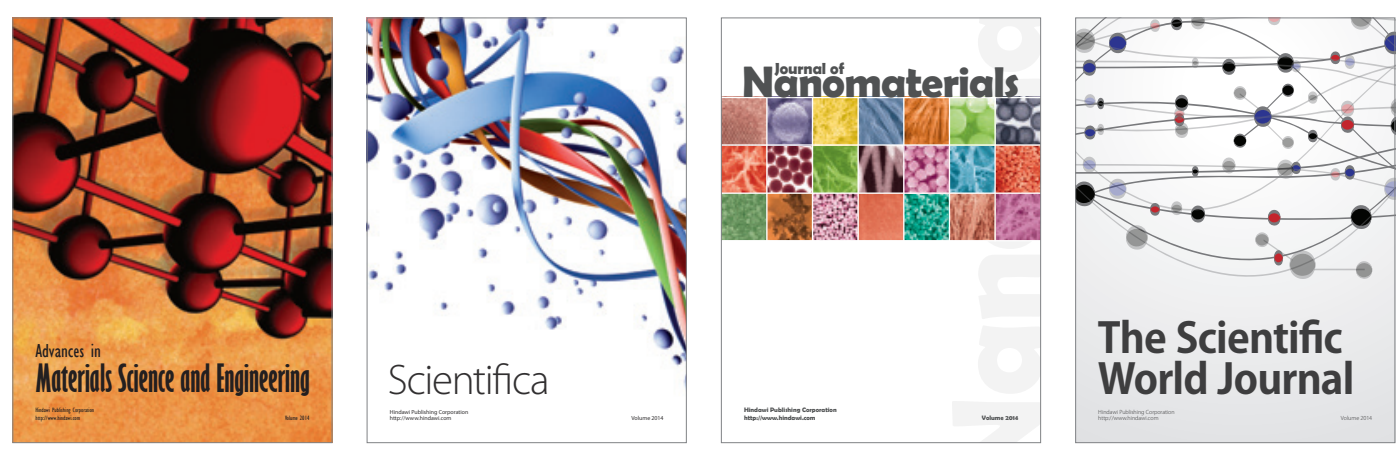

\section{The Scientific World Journal}
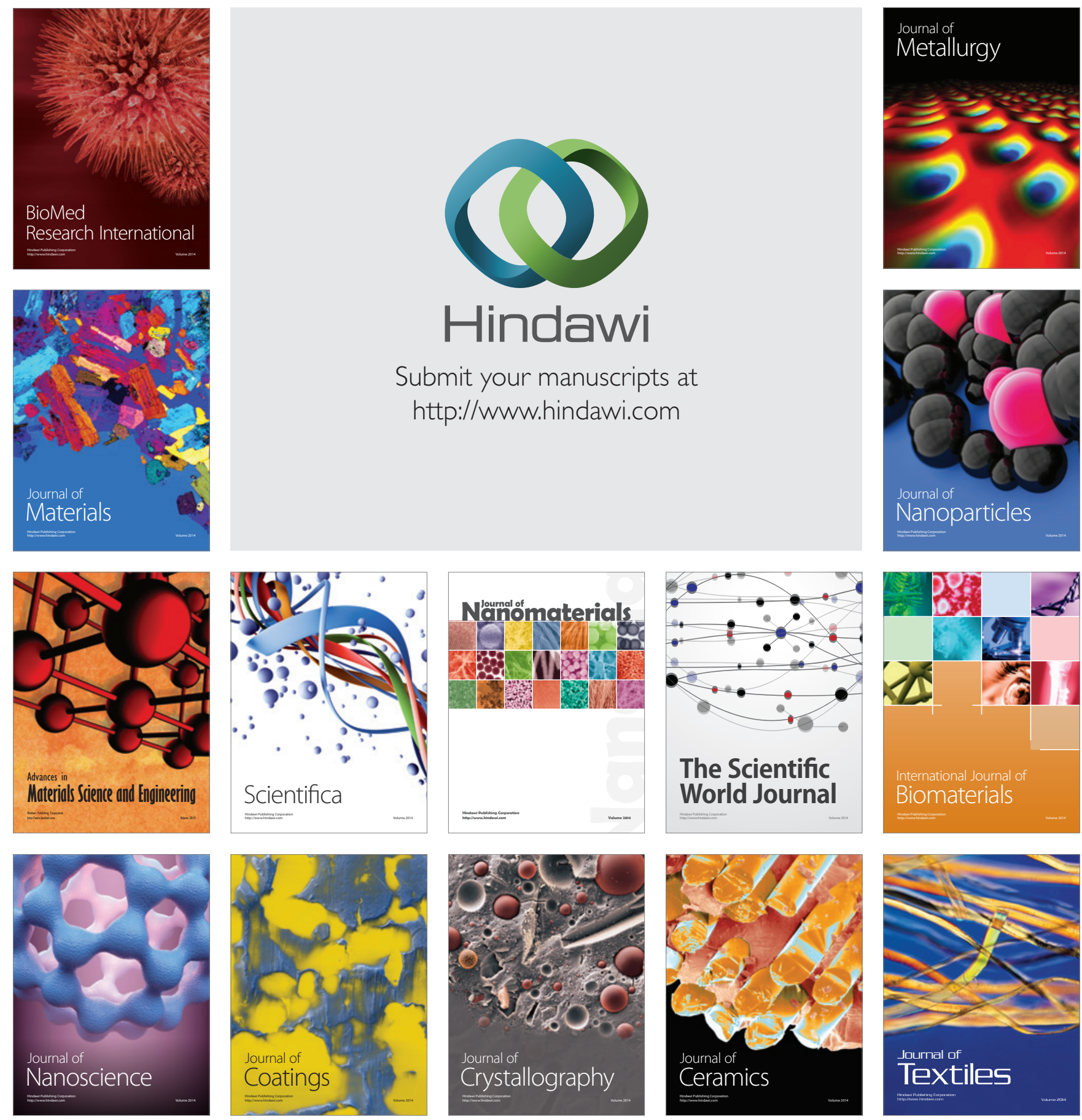